\title{
Patient Experiences at Enhanced-Service Pharmacies in lowa
}

Chen Huang, Graduate Student ${ }^{1}$; William R. Doucette, PhD, FAPhA, RPh ${ }^{1}$; Michael Andreski, RPh, PhD²; Anthony Pudlo, PharmD, MBA Vice President, Professional Affairs ${ }^{3}$

${ }^{1}$ College of Pharmacy University of lowa; ${ }^{2}$ College of Pharmacy Drake University; ${ }^{3}$ lowa Pharmacy Association

\begin{abstract}
Objectives: As payment systems are evolving, the role of community pharmacists has expanded from simply dispensing prescriptions to actively providing care to patients. Little is known about patients' experiences with enhanced pharmacy services under the pay-forperformance model. In lowa, Wellmark implemented its Value-Based Pharmacy Program (VBPP) where pharmacists receive capitation for performance on a set of quality measurements. Therefore, the objective of this study was to evaluate the quality of services and pharmacies from patients' perspective in VBPP. A structured interview guide developed from the service quality model was used for this study. Methods: We conducted telephone interviews with patients from 6 community pharmacies participating in VBPP between December 2017 and January 2018. Patients who were aged between 21 and 90 years, had Wellmark prescription drug coverage, were currently on at least three medications with one or more of the medications for a chronic condition and had received enhanced pharmacy services were invited for the study. The semi-structured interview transcripts were coded and analyzed using an inductive approach of thematic analysis. Results: Interviews were completed by 25 patients. Most of them were female and the average age was 59. More than half of the patients were taking at least five medications for chronic conditions. A majority of the patients received medication synchronization and immunization. A total of 13 themes across the service quality dimensions were identified. Patients thought their pharmacists were reliable, responsive, knowledgeable and trustworthy when they provided services. Pharmacy services were accessible and perceived as high quality. Privacy was not a big concern for most patients. Patients had a somewhat limited view regarding how pharmacists helped them maintain health. Conclusions: Patients' perceptions of enhanced pharmacy services and pharmacies were generally positive while their understanding of pharmacists' clinical role was limited.
\end{abstract}

Keywords: pharmacist service, service quality, patient

\section{Introduction}

Community pharmacists are one of the most accessible healthcare professionals in delivery of primary care for patients. In recent years, the role of community pharmacists has expanded from simply dispensing and distributing prescriptions to actively involving a variety of health-related services [1-3]. A growing body of evidence demonstrates that community pharmacists play a key part in patient care, including providing medication therapy review, improving medication adherence and safety, helping to reduce unnecessary costs and facilitating inter-professional collaboration [4-9].

The 2017 NCPA Digest found that community pharmacists are experiencing lower reimbursements for filling prescriptions while they are expanding the scope of services. As payers continue to put pressure on payments, the traditional volumebased payment model in which pharmacists used to be reimbursed is eroding. Under the context that the US healthcare system is making progress toward pay-forperformance models, [10-11] community pharmacists now are at the forefront of this volume to value transition. The concept

Corresponding author: William R. Doucette, PhD, FAPhA, RPh Professor, University of lowa College of Pharmacy

115 S Grand Ave, lowa City, IA 52242

Email: william-doucette@uiowa.edu of pay-for-performance was introduced for aligning healthcare provider payments with value. In pharmacy practice, instead of being paid merely by prescription volume, pharmacists can receive extra rewards by enhancing the quality of patient care. Several pay-for-performance programs were initiated and have achieved promising results including cost-saving and better patients' outcomes [12-15]. In a pilot program [16], lowa's major payer and a progressive community pharmacy worked together to determine whether regular pharmacy interventions could bring cost-saving changes and optimize care. In total, about 600 patients participated in the pilot study. These patients received enhanced pharmacist services including continuous medication monitoring, risk assessment, and comprehensive medication reviews. That one-year initiative turned out to have significantly lower per person monthly costs when compared to a matched group of patients not receiving the enhanced pharmacist services. Based on the success of this program, Wellmark created a value-based pharmacy program (VBPP) where pharmacies are able to receive bonus payments tied to patients' outcomes and lower costs. As this program is rolled out, community pharmacists in lowa have begun to implement the enhanced pharmacy services into their daily work in order to optimize medication therapy for patients in their communities.

Since these payment models are still emerging, little is known about patients' experiences with services in community pharmacies under the pay-for-performance structure. Yet, 
patients are key parties in properly managing chronic conditions and associated medication therapy. Assessing patient experiences would provide an important view of the effects of receiving services at pharmacies participating in Wellmark's value-based pharmacy program. In addition, patients' experiences likely are related to their health behaviors such as medication adherence [17-18]. Thus, patients' experiences can serve as an important indicator of enhanced pharmacy services delivered, and reflect patients' beliefs of how well these services meet their expectations. For example, satisfied patients may be more likely to continue to use enhanced pharmacy services, maintain good relationships with pharmacists, have good medication adherence and improve health outcomes [19-21].

In pharmacy, work has been done to assess patients' experiences through patient satisfaction with pharmacy services [22-25], as well as a patient experience survey (Consumer Experience with Pharmacy Services Survey (CEPSS) [26-27]. The satisfaction measures tended to focus on pharmaceutical care, which served as a model of pharmacy practice prior to medication management. For example, the Pharmaceutical Care Satisfaction Questionnaire had four dimensions: Provision of Pharmaceutical Care, Patient Understanding, Patient Empowerment, and Pharmacist-Patient Relations [23]. Though there is some overlap with the enhanced pharmacy services of today (e.g. medication synchronization, immunizations), the previous measures of patient satisfaction with pharmacy services do not appear to capture the patient experiences in these community pharmacies. The CEPSS addressed four aspects of pharmacy services: General Staff Communication, Health and Medication-Focused Communication, Pharmacy Care and Clarity of Written Information [27]. While the CEPSS focuses on information exchange between a pharmacist and patient, it does not address technical issues and timeliness of pharmacist services.

Another approach to evaluating patients' experiences with enhanced pharmacy services is a service quality model $[19,28]$. Under this approach, service quality is a patient's perception that results from comparing expected service with perceived (received) service. The SERVQUAL model developed by Parasuraman and colleagues contained ten determinants of service quality ratings by consumers: reliability, responsiveness, access, security, competence, credibility, communication, courtesy, understanding/knowing the customer, and tangibles. Reliability involves consistency of service delivery. Responsiveness deals with the readiness of employees to provide a service, relating to timeliness of service delivery. Access is concerned with the approachability of service personnel (e.g. pharmacist). Security refers to confidentiality and privacy around the service. Competence means the possession of the knowledge and skills needed for quality service delivery. Communication involves using language that customers can understand (i.e. health literacy) and listening to them. Courtesy means showing respect and consideration. Understanding/knowing the customer refers to efforts made to know the customer's needs. Tangibles include the physical facilities and other components of the service. The breadth of this service quality model made it attractive to assess patient experiences with community pharmacies delivering enhanced services. The purpose of this study was to collect patients' feedback about services received at progressive community pharmacies. The specific objective was: 1) To use a service quality model to characterize qualitative feedback from patients receiving services from pharmacies participating in Wellmark's value-based pharmacy program.

\section{Methods}

Six lowa pharmacies participating in the VBPP were recruited to assist the research team identify eligible patients as potential study subjects. The pharmacies had completed a previous online survey about their practices. Patients were eligible if they met the following inclusion criteria: 1) aged between 21 years and 90 years, 2) had prescription drug coverage under the VBPP, 3) were currently on three or more medications with at least one of the medications for a chronic condition and 4) had received at least one enhanced pharmacy service including medication synchronization, medication management (e.g. MTM), disease state management, immunization or continuous medication monitoring.

This study used an opt-in recruitment process. Each pharmacy was asked to identify 40 of their patients based on the inclusion criteria. Each pharmacy was given 40 study invitation packets from the research team. Within each invitation packet, there was an invitation letter describing the study and a contact card (WRD's phone number and email address) for patients to use if they wanted to opt-in or learn more about the study. In addition, the letter included the elements of consent for patients to read through. Pharmacists in each pharmacy were responsible for filling in names of the 40 patients onto the envelopes and mailing them on behalf of the research team. Once pharmacists sent their 40 invitation packets, the research team was notified and started a two-week waiting window for patients to opt-in the study. If a patient called in and agreed to participate, a phone interview would be scheduled at the patient's earliest convenience. All participating patients needed to provide their phone numbers so the research team could contact them to conduct the interview. If patients called in and did not want to participate, they would be thanked and no longer contacted. The study was reviewed by the Institutional Review Board at the University of lowa.

A structured interview guide developed from the service quality model [19] was used for the phone interview. Patients were asked about their experiences with the enhanced pharmacy services received at their pharmacies. Interview questions concentrated on seven service quality components (reliability, responsiveness, access, security, competence, credibility, communication) and how pharmacists helped patients maintain health. Applied to community pharmacy services, the 
seven service quality components examined patients' overall quality perception of services, including the service provider and facility. During the interview, patients were asked about how the services were delivered, how well the services met their expectations about them, how well they understood what the pharmacist told them during the service, their professional relations with the pharmacist, why they go to that pharmacy and how pharmacists help patients stay healthy. Each patient received compensation (i.e. gift card) for participating in the study.

Each telephone interview was audiotaped and transcribed verbatim. In order to maintain confidentiality, all patient identifiers were removed before transcribing, and a unique case identifier was used for each patient interview. The qualitative interview transcripts were coded and analyzed using an inductive approach of thematic analysis. There were three stages for the thematic analysis. The first stage involved open coding by two coders to segment data into meaningful words or short sequence of words. The second stage involved code validation so the coders repeatedly read and discussed the transcripts to make sure the consistency and validation. In the third stage, the research team categorized codes into service quality components and made associations with codes in the same component that referred to similar themes, systematically compared and finalized each theme. In addition, responses to descriptive variables from the participating pharmacies to an online baseline survey were tabulated to describe the set of six pharmacies.

\section{Results}

A total of 25 patients participated in this study and all of their interviews were audiotaped and transcribed. Each telephone interview lasted 20-30 minutes. Most of the patients were female (72\%) and the average age was 59 (Table 1). More than half of the patients were taking at least five medications for their chronic conditions. A majority of the patients received medication synchronization and immunization from their pharmacies.

Data from the on-line surveys (Table 2) showed that these six pharmacy practices reported having an average of about 3.5 FTEs of pharmacists/pharmacy residents and 5.7 FTEs of pharmacy technicians employed. All of them stated that they provide immunizations, help manage diabetes, and provide adherence packaging to their patients. Five of six reported providing services for hyperlipidemia, medication therapy management, medication reconciliation, medication synchronization, and adherence education (Table 3).

We identified 13 themes across seven service quality dimensions and one on pharmacists helping patients stay healthy (Table 4). In summary, patients thought their pharmacists were reliable, responsive, knowledgeable and trustful when they provided services. Pharmacy services were accessible and perceived as high quality. Privacy was not a big concern for most patients. Patients had a somewhat narrow view regarding how pharmacists helped them maintain health.

\section{1 (Reliability) Patients appreciated the benefits of medication synchronization.}

When patients received enhanced pharmacy services such as medication synchronization, they expected their pharmacists to dispense the medications correctly. Pharmacists did a good job in going through the whole process and details when patients first used this service. Once the pharmacy staff had synced all the medications, they called or emailed patients and sometimes patients called pharmacies to see if their medications were ready. Patients gave positive reviews for this service because it was flexible, helped budget their monthly payments and saved transportation costs.

- The pharmacy has synced all my medicines when they can be refilled and then they call the house phone and leave a message that the meds can be picked up and are ready to go. [P6]

- (Medication sync) We love it. It helps us budget our monthly payments. We thought it was a good idea when they initially contacted us, and we think it's a great idea now, and it works. [P9]

- (Medication sync) It's never been a really planned thing, I just would stop in and, you know order and call whoever was on the phone when I was about out. The fact that they knew my prescriptions would be coming due and they actually had them all packaged up and waiting for me. [P25]

Many patients agreed that medication synchronization saved them trips to the pharmacies, especially when patients' family members were on the same cycle.

- (The main benefit for using medication sync) I've been able to get my husband and I on the same cycle so that we only have to make one stop every month instead of two or three. Just so we make fewer stops. [P2]

- This (medication sync) program that we're in is wonderful. We just go in, it's ready, we pick it up, and we go home. [P9]

\section{2 (Reliability) Patients found pharmacists instrumental in providing vaccinations.}

Patients were satisfied with getting vaccinated at pharmacies. Pharmacists were informative when they explained the flu vaccine or shingles vaccine to patients and made sure they took care of all the people in need.

- (Vaccination) This is the first year I got it there. I was there picking up a prescription and saw the sign and asked if they could do our flu shot as well. It was nice to be able to just do it there. She did a good job going over all of the details for the flu shot, and gave us the shot and everything was good. They did a good job calming them (kids) down and getting us all through in a timely manner. [P14] 
- (Shingles shot) They gave me a printout of what to expect. They explained it before they actually gave it to me, so they were very informative. It was made a good experience. Made it as good as a shot can be. [P16]

\section{1 (Responsiveness) Patients valued pharmacists' readiness} to serve.

Patients spoke highly of pharmacists' readiness to serve. If patients had any questions, pharmacists were willing to answer. Pharmacists responded well and were very good at offering advice.

- If I happen to have any questions about it, they certainly are free to answer, to help me. It's really as you've gone in, you've been able to get questions answered. [P3]

- They've always been great with anything that I've ever had to talk to them about, or so. I don't really remember questions not really being answered, or at least given more information of what I could do, I guess. [P5]

- They're wonderful. They answer every question I have. If they can't, they find somebody there that can. [P23]

2.2 (Responsiveness) Pharmacists were responsive to patients' needs.

Pharmacists were detailed-oriented in that they work hard to assure patients' understanding of their medications. When patients had problems with their medications, pharmacists were very responsive and handled problems professionally.

- They always will answer anything I ask. I was trying some new medication, and I was dizzy. I'd just call then I told them what was happening, so they always get me in touch with the right person if I need a question that they can't just tell me. They're really responsive to whatever I needed through the years. [P2]

- They're very responsive here, they're very helpful. They go over and above to make sure that you take your medicine the way it should be. They have quite a few techs that work there too and they know quite a bit too but if they don't know they'll go to the pharmacist. P16]

3.1 (Access) Convenience was important for patients in selecting pharmacies.

Convenience was a top reason patients gave when asked about why they chose their current pharmacies. Some patients preferred pharmacies near or within grocery stores so they could pick up prescriptions when they went to buy food and some patients preferred pharmacies near work places or clinics.

- I guess it pretty much started first as convenience. It was close to where I worked. [P4]

- It's a half block down the street from where I work. [P15]
- I just feel satisfied. It's convenient also, it's right next to our grocery store. So it's just real convenient to stop and get your medicines anytime you go to the grocery store. [P16]

- The physician's clinic where I go is located there. It's a small town, everybody knows everybody. If we have questions, like between doctor and pharmacist, it's real easy to take care of it. [P21]

3.2 (Access) Patients living in small towns had limited choices. For patients living in small towns, there usually is only one pharmacy. The limitation in choice didn't affect the quality of pharmacy services, although some patients considered going to pharmacies out of town only if they were cheaper. A concern was the operating hours since some small pharmacies didn't open regular hours on weekends.

- The only con about going there is they are only open Saturday till noon. So if you're trying to get stuff like on the weekend you can't get meds on Saturday or Sunday. [P7]

- Super convenient so I've just known them for years, for 18 years, and I've just always had good service with them and I just really like their delivery service. [P10]

- I always have done things in the community where I live, and I hate to go out of town to see if I could get it cheaper. I go because this is the local pharmacy, that's why I usually do it, but if I could get it cheaper and I thought they would do a good job, I might do that. [P13]

\section{3 (Access) Patients were open to appointments when needed.}

Patients believed an appointment could be used, if someone needed a comprehensive medication review or in-depth discussion with pharmacists since these services took more time than average services. In addition, making an appointment in advance was seen to bring convenience and flexibility to patients since they wouldn't need to wait long for dispensing because extra staff would be there to cover the appointments and dispensing process.

- I think it's a good thing because there's times when you may want to discuss something more in-depth than the time you would stand at a counter or whatever. It doesn't tie them up at inopportune times. [P4]

- There have always been others waiting for their prescriptions, so I think an appointment is a good idea. [P9]

- I think that would make sense. I mean, for people like my parents, my mom's a diabetic and she's on several different medications, I think that would be great. Right now we personally are not at that point, but for anybody who takes several medications, I think that's a good thing. That way, when you get there, you know you're gonna be able to talk to somebody right away instead of just standing in line. [P22] 
- I actually had an appointment for my new machine (CPAP machine). You can sit there, they'll tell you everything about what you need, they explain everything. If you have questions, you could ask questions. You know that they're not going to be rushed. [P23]

\section{1 (Security) Patients didn't see problems with privacy in pharmacies.}

Pharmacists were sensitive to privacy concerns. Therefore, privacy was not a big problem for most patients. According to patients' experiences, if they needed space to talk about their medications or have some more personal discussions, pharmacists would take them to a private or semi-private area where other people were not able to overhear the discussion.

- I Iuess I don't have a problem with that. I think it's fine. (Privacy) If I wasn't comfortable, where in the setting we're at, or where we were discussing, that I would ask for something more private. [P5]

- $\quad$ (privacy) I really wouldn't have minded if they did it in front of the counter, in front of a lot of people. It's not a big deal. (picking up medications) they take care to not really say what they are. They seem to be sensitive to privacy concerns. [P11]

- (privacy) They have an area that is fairly private. So if you really needed to sit down and discuss your medicines, then they can shut the door. It's pretty good. [P19]

\section{1 (Competence) Patients recognized pharmacists'} knowledge about medications.

Patients found pharmacists and other staff in the pharmacies were well trained and knowledgeable. Pharmacists went above and beyond patients' expectations and were proactive with patients, such as helping them figure out questions for which they were not able to get satisfactory answers from doctors.

- They are very knowledgeable. And I can tell you that not from experience, but my experience with my children, that even if they're not really knowledgeable about something, they'll take the extra effort to find a little bit more out about it. [P5]

- Beyond what they should have to do. They go above and beyond the call, I think. Excellent. They've been always very nice. Very knowledgeable. [P8]

- (Medication management) I couldn't seem to really get any answers out of the doctor so I visited with my pharmacist and they helped me through my doctor on figuring out which medication is for what. I feel that that was management. It helped clarify what we were doing. [P12]

- They met my expectations very well. We have an excellent pharmacy and our pharmacist is great. [P15]
6.1 (Credibility) Patients trusted advice from pharmacists on medications.

When counselling patients about their medications, pharmacists went over side effects with the patients, checking what the patients needed to know. For example, one pharmacist helped a patient compare pain management medications when concerned about possible addiction risk. At times when pharmacists monitored the effects of medications, they were able to obtain laboratory reports. Patients believed they could trust pharmacists wholeheartedly and sometimes they preferred pharmacists over doctors.

- (Medication management) I just wasn't real sure that I wanted to take it (narcotics) and they went over you know the side effects with me. Then again they called the doctor to see if there's anything else I could take you know. I just settled on ibuprofen because I wasn't in that much pain. In fact sometimes I would rather talk to them than I would the doctor. [P15]

- (Monitoring the effects of medications) Cause it's mostly cholesterol and thyroid so they just ask me if my labs have been drawn lately. They provide a very good service to my family and you can always trust what they do. [P19]

- My pain management issues and just chatting with one of those folks about, things I was already taking, which anti-inflammatory in my mix, and then what I should and shouldn't be taking, certain amounts like of ibuprofen with that particular anti-inflammatory and alternatives to that and also what type of specific pain pill, whether I want hydrocodone or a different pain management tool. You know, with the concern of opioid addiction so. And also if I had a preference, because some people want to avoid that situation so they choose a different pain product. [P25]

\section{2 (Credibility) Patients saw value in a good relationship with pharmacists.}

In addition, patients believed it was very important to build a good relationship with their pharmacists because they were the people who knew the medications. If there was anything wrong, pharmacists were the ones patients could count on. Such familiarity can support safe and effective medication use.

- I would say very important (to have good relationship with a pharmacist). Medication can be very harmful to you if it's not explained how to take it and understood. [P20]

- I trust them for whatever they need to do, because they really do know and they look for med reactions. [P19]

\section{1 (Communication) Patients rated communication with pharmacists highly. \\ Pharmacists typically established effective communication with their patients. Pharmacists made medical terminology particularly understandable. When they explained medication, health conditions or services to patients, they answered patient}


questions effectively. Patients found pharmacists were good listeners as well.

- I'm not that well-educated. I think anytime they've ever told me anything, they have explained it very well. Down to my terms, anyway. I know there's bigger words for them than what they use. [P8]

- She puts it on my level, If I don't, she'll you know repeat it, or you know ask me if I understand it or anything. [P15]

- They look at me when I'm talking to them, and they listen to what I'm asking for and they take care of business. They're good. [P17]

\subsection{Patients viewed medication provision as pharmacists' role in maintaining their health.}

Patients' views regarding how pharmacies helped them maintain health focused on medications. Many patients thought pharmacists helped them by preparing their prescriptions and clarifying medication-related questions. Patients felt relief after they interacted with pharmacists.

- By making sure that I do get my prescriptions. Other than just picking up a prescription, you know they're concerned. [P15]

- My medication, I guess. And tell me how to take it and take care of myself. Keep me in health, I guess. [P20]

- If it was going to cause serious health problems, I'm not sure I'd want to keep taking it. But the way he explained it, you can have one problem where you can eliminate it and then you've got a bigger problem. He gave me choices and made me feel better about staying on the regimen I was on. [P21]

Pharmacists also ensured vaccination information was delivered and highlighted the importance of healthy lifestyle.

- They're always asking me if I'm drinking enough water, if I'm getting enough sleep, have I taken my medicine at the right time. This year they made sure I had a flu shot 'cause I had a bad year last year being sick. They just seem to care about you. [P23]

- They are looking over your meds to make sure they do not cause further problems or complications. They offer, course, the idea of the vaccinations depending on what it is. You can get those done close to home and easily. I'd say those are the main points. [P25]

\subsection{Not all contributions of pharmacists to patient health are apparent.}

However, some patients didn't recognize pharmacists' contributions to their health. This likely relates to pharmacists performing cognitive activities that are not readily visible to patients. These patients viewed their physicians as their main health advisor and decision maker.

- I don't think they do. I think it's up to the doctor. You might be able to ask them a certain question, and they might be able to answer it, but I don't think overall they're not looking at your particular health. [P13]

- I would say $10 \%$, you know. [P12]

\section{Discussion \& Conclusion}

Two service quality dimensions, Access and Security, together addressed patients' experiences in accessing medications and pharmacists. Convenience was identified as important in selecting pharmacies, especially in rural communities. Previous studies of pharmacy patronage motives identified convenience of location as one of the top factors found to be strongly and positively associated with patients' satisfaction with community pharmacies and their services [20-21, 29-30]. Arneson et al. [31] conducted a study to determine which pharmacy attributes could influence consumers' choice of pharmacies and the results showed that convenient location was an important reason that consumers patronized a neighborhood pharmacy. In a study of medication usage among an elderly population, [32] Ostrom et al. found a major reason for choosing a particular pharmacy was location. Another study [33] found the pharmacy patronage of elderly people was affected by the relationship between individual's residence and pharmacy's location. A convenient location was described in several ways by respondents in this study, including being near other shopping, near a clinic, and near work.

Ready access to the pharmacy was an attribute for patients selecting a pharmacy. Another notion of convenience raised in this study was that the pharmacy was only a pharmacy, and the patient did not have to go through people shopping for groceries or other goods. These patients preferred their pharmacy because it was not located inside a large retail center, which presents a different perspective on convenience - that of little interference in obtaining their prescription medications. Future research is needed to better understand what types of patients might prefer making an extra stop at a smaller, more accessible pharmacy instead of going to one within a larger retail space.

When asked about using an appointment in a community pharmacy to receive a service that lasted longer than usual, most patients were in favor of the idea though not many had actually used such an appointment. The assumption was that extra staff would be available to cover the appointments, while the usual staff kept the other services (e.g. dispensing) going as usual. The respondents saw the value of appointments for themselves and for other pharmacy patrons, who could benefit from more time with a pharmacist. While some community pharmacies use appointments for particular services, not all community pharmacies are doing so. These findings suggest that consumers could be willing to utilize appointments for care with longer service episodes.

The Security issue focused on having adequate privacy while receiving services in the pharmacy. Many participants said that their pharmacy had an area that provided extra privacy if 
needed, including a counseling area behind a small divider on a counter, a cubicle or a separate room. It is possible that as pharmacies provide new services related to medication monitoring and disease state management that more sensitive conversations will occur there. Perhaps patient privacy would be more of an issue in those situations, but at this time there seems to be little concern about privacy in these pharmacies. A number of previous studies explored possible staff-patient conversation disclosures during patient counseling and the influence of counter design on privacy [34-39]. In this previous work, patients tended to be more reserved about having conversations with pharmacists and they needed to provide personal information (e.g. medical history). Patients tended to be more satisfied if they were at enclosed counters and a queue was at distance from them in the pharmacy. Patients with specific conditions (e.g. mental illness), usually had higher needs for privacy and confidentiality. In a study [40] of mental health patients' experiences with community pharmacy services, participants recommend adding additional privacy and comfortable space to the environment when waiting for prescriptions. The contrast between this study and previous findings could relate to having a more rural patient sample and the absence of pharmacies in large retail chains in the sample. These factors could affect how the patients and the pharmacy environment influence patient perceptions of privacy.

Several pharmacist characteristics were discussed, under the Competence, Credibility and Communication dimensions of service quality. Regarding Competence, the patients readily recognized pharmacists' knowledge about medications. One patient described going to the pharmacist for help in clarifying the purpose of her medications when she could not get satisfactory answers from her physician. She found the pharmacist communication helpful in understanding her medication therapy. Related to this was patients reporting that they trusted the advice they received from the pharmacist (Credibility). Most respondents stated that having a good relationship with a pharmacist was valuable to them and their family. They valued and trusted the information that the pharmacists provided about managing their medications and health. These findings are consistent with previous research on pharmacist-patient relationship quality reported by WorleyLouis, [41] that found positive associations between relationship quality (comprised of trust and satisfaction) and pharmacist-patient communication. In addition, a pharmacist giving accurate information to patients was positively linked with relationship quality. It appears that the respondents in this sample of pharmacies have favorable relationship quality with their pharmacists.

Study participants talked about the pharmacists' Reliability and Responsiveness in meeting their healthcare needs through medication and drug information. One relatively new service, medication synchronization, was valued as a reliable approach to getting their chronic medications. Some patients mentioned that they liked making fewer trips to the pharmacy, and appreciated assistance with coordinating refills across family members. Our findings are consistent with the high patient satisfaction ratings of patients using a medication synchronization service [42]. While not all medications can be synchronized, many patients appreciated the benefits from this service. In a similar manner, the participants reported that their pharmacists were responsive to their needs, whether in assisting with obtaining medications, handling insurance issues, or working with providers. The patients stated that the pharmacist readily did what they needed to resolve an issue or answer a question.

When asked about how their pharmacist helped them maintain their health, most respondents talked about providing the medications that they needed. The patients rely on their pharmacists to dispense the correct medications in a timely manner. Some participants also talked about the usefulness of drug and more general health information provided at pharmacies. A few patients had difficulty in answering the question, stating that they weren't sure how pharmacists helped them stay healthy. This last answer could relate to some of the cognitive services performed by pharmacists not being readily visible to patients. For example, the benefits of a pharmacist checking for drug interactions or therapeutic duplications when dispensing a new medication may not be apparent to patients. It may be worthwhile for pharmacists to better inform patients about the actions they perform in the dispensing process.

In summary, patients thought their pharmacists were reliable, responsive, knowledgeable and trustworthy when they provided services. Pharmacy services were accessible and perceived as high quality. Privacy was not a big concern for most patients. Patients had a somewhat limited view regarding how pharmacists helped them maintain health.

\section{Funding: Community Pharmacy Foundation}

Conflicts of Interest: We declare no conflicts of interest or financial interests that the authors or members of their immediate families have in any product or service discussed in the manuscript, including grants (pending or received), employment, gifts, stock holdings or options, honoraria, consultancies, expert testimony, patents and royalties.

Treatment of Human Subjects: This study was approved by the Institutional Review Board at the University of lowa. 


\section{References}

1. Manolakis, P.G. and J.B. Skelton, Pharmacists' Contributions to Primary Care in the United States Collaborating to Address Unmet Patient Care Needs: The Emerging Role for Pharmacists to Address the Shortage of Primary Care Providers. American Journal of Pharmaceutical Education, 2010. 74(10): p. S7.

2. Chisholm-Burns, M.A., J. Kim Lee, C.A. Spivey, M. Slack, R.N. Herrier, E. Hall-Lipsy, et al., US Pharmacists' Effect as Team Members on Patient Care: Systematic Review and Meta-Analyses. Medical Care, 2010. 48(10): p. 923-933.

3. George, P.P., J.A.D. Molina, J. Cheah, S.C. Chan, and B.P. Lim, The evolving role of the community pharmacist in chronic disease management - $a$ literature review. Annals of the Academy of Medicine, Singapore, 2010. 39(11): p. 861-7.

4. Mossialos, E., E. Courtin, H. Naci, S. Benrimoj, M. Bouvy, K. Farris, et al., From "retailers" to health care providers: Transforming the role of community pharmacists in chronic disease management. Health policy (Amsterdam, Netherlands), 2015. 119(5): p. 628-39.

5. Bryant, L.J.M., G. Coster, G.D. Gamble, and R.N. McCormick, General practitioners' and pharmacists' perceptions of the role of community pharmacists in delivering clinical services. Research in Social and Administrative Pharmacy. 5(4): p. 347-362.

6. Taitel, M., J. Jiang, K. Rudkin, S. Ewing, and I. Duncan, The impact of pharmacist face-to-face counseling to improve medication adherence among patients initiating statin therapy. Patient preference and adherence, 2012. 6: p. 323-9.

7. Wijk, B.L.V., O.H. Klungel, E.R. Heerdink, and A.d. Boer, Effectiveness of Interventions by Community Pharmacists to Improve Patient Adherence to Chronic Medication: A Systematic Review. Annals of Pharmacotherapy, 2005. 39(2): p. 319-328.

8. Chisholm-Burns, M.A., J. Kim Lee, C.A. Spivey, M. Slack, R.N. Herrier, E. Hall-Lipsy, et al., US pharmacists' effect as team members on patient care: systematic review and meta-analyses. Medical care, 2010. 48(10): p. 923-33.

9. Carter, B.L., H.B. Bosworth, and B.B. Green, The hypertension team: the role of the pharmacist, nurse, and teamwork in hypertension therapy. Journal of clinical hypertension (Greenwich, Conn ), 2012. 14(1): p. 51-65.

10. Porter, M.E., A Strategy for Health Care Reform Toward a Value-Based System. New England Journal of Medicine, 2009. 361(2): p. 109-112.

11. Bowling, B., D. Newman, C. White, A. Wood, and A. Coustasse, Provider Reimbursement Following the Affordable Care Act. The health care manager, 2018.
12. Koenigsfeld, C.F., K.K. Horning, C.D. Logemann, and G.A. Schmidt, Medication Therapy Management in the Primary Care Setting:A Pharmacist-Based Pay-forPerformance Project. Journal of Pharmacy Practice, 2012. 25(1): p. 89-95.

13. Lenz, T.L. and M.S. Monaghan, Pay-for-performance model of medication therapy management in pharmacy practice. Journal of the American Pharmacists Association. 51(3): p. 425-431.

14. Pringle, J.L., A. Boyer, M.H. Conklin, J.W. McCullough, and A. Aldridge, The Pennsylvania Project: pharmacist intervention improved medication adherence and reduced health care costs. Health affairs (Project Hope), 2014. 33(8): p. 1444-52.

15. Berdine, H.J. and M.L. Skomo, Development and integration of pharmacist clinical services into the patient-centered medical home. Journal of the American Pharmacists Association. 52(5): p. 661-667.

16. Doucette, W.R., R.P. McDonough, F. Herald, A. Goedken, J. Funk, and M.J. Deninger, Pharmacy performance while providing continuous medication monitoring, in Journal of the American Pharmacists Association. 2017, Elsevier. p. 692-697.

17. Wong, E.L.Y., A. Coulter, P. Hewitson, A.W.L. Cheung, C.H.K. Yam, S.f. Lui, et al., Patient Experience and Satisfaction with Inpatient Service: Development of Short Form Survey Instrument Measuring the Core Aspect of Inpatient Experience. PLOS ONE, 2015. 10(4): p. e0122299.

18. Ware, J.E. and A.R. Davis, Behavioral consequences of consumer dissatisfaction with medical care.

Evaluation and Program Planning, 1983. 6(3): p. 291297.

19. Parasuraman, A., V.A. Zeithaml, and L.L. Berry, $A$ Conceptual Model of Service Quality and Its Implications for Future Research. Journal of Marketing, 1985. 49(4): p. 41-50.

20. Carroll, N.V. and A.W. Jowdy, Demographic and Prescription Patronage Motive Differences Among Segments in the Community Pharmacy Market. Journal of Pharmaceutical Marketing \& Management, 1987. 1(4): p. 19-33.

21. Naik Panvelkar, P., B. Saini, and C. Armour, Measurement of patient satisfaction with community pharmacy services: a review. Pharmacy World \& Science, 2009. 31(5): p. 525-537.

22. Schommer JC, Kucukarslan SN. Measuring patient satisfaction with pharmaceutical services. Am J Health-Syst Pharm. 1997;54:2721-32.

23. Gourley GK, Gourley DR, La Monica Rigolosi E, Reed P, Solomon DK, Washington E. Development and validization of the Pharmaceutical Care Satisfaction Questionnaire. Am J Manag Care. 2001;7:461-66. 
24. Larson LN, Rovers J, Mackeigan LD. Patient satisfaction with pharmaceutical care: Update of a validated instrument. J Am Pharm Assoc. 2002;42:4450.

25. Traverso ML, Salamano M, Botta C, Colautti M, Palchik V, Perez B. Questionnaire to assess patient satisfaction with pharmaceutical care in Spanish language. Int J Qual Health Care. 2007;19:217-24.

26. Blalock SJ, Keller S, Nau D, Frentzel EM. Development of the Consumer Assessment of Pharmacy Services survey. J Am Pharm Assoc. 2012;52:324-332.

27. Shiyanbola OO, Mott DA, Croes KD. Using the Consumer Experience with Pharmacy Services Survey as a quality metric for ambulatory care pharmacies: Older adults' perspectives. BMJ Open. 2016;6:e011241.

28. Parasuraman A, Zeithaml VA, Berry LL. SERVQUAL: A multiple-item scale for measuring consumer perceptions of service quality. J Retailing. 1988;64(1):12-40.

29. Briesacher, B. and R. Corey, Patient satisfaction with pharmaceutical services at independent and chain pharmacies. American Journal of Health-System Pharmacy, 1997. 54(5): p. 531.

30. Tom Xu, K., Choice of and Overall Satisfaction With Pharmacies Among a Community-Dwelling Elderly Population. Medical Care, 2002. 40(12): p. 1283-1293.

31. Arneson, D.L., E.W. Jacobs, D.M. Scott, and W.J. Murray, Patronage Motives of Community Pharmacy Patrons. Journal of Pharmaceutical Marketing \& Management, 1989. 4(2): p. 3-22.

32. Ostrom, J.R., E.R. Hammarlund, D.B. Christensen, J.B. Plein, and A.J. Kethley, Medication Usage in an Elderly Population. Medical Care, 1985. 23(2): p. 157-164.

33. Schommer, J.C., The Effect of Age on Pharmacy Patronage: Is Locational Convenience a Lurking Variable? Journal of Pharmaceutical Marketing \& Management, 1994. 9(1): p. 33-46.

34. Seubert, L.J., K. Whitelaw, F. Boeni, L. Hattingh, M.C. Watson, and R.M. Clifford, Barriers and Facilitators for Information Exchange during Over-The-Counter Consultations in Community Pharmacy: A Focus Group Study. Pharmacy: Journal of Pharmacy Education and Practice, 2017. 5(4): p. 65.

35. Hattingh, H.L., L. Emmerton, P. Ng Cheong Tin, and C. Green, Utilization of community pharmacy space to enhance privacy: a qualitative study. Health Expect, 2016. 19(5): p. 1098-110.

36. Beardsley, R.S., C.A. Johnson, and G. Wise, Privacy as a Factor in Patient Counseling. Journal of the American Pharmaceutical Association (1961), 1977. 17(6): p. 366-368.
37. Banks, J., A. Shaw, and M.C. Weiss, The community pharmacy and discursive complexity: a qualitative study of interaction between counter assistants and customers. Health Soc Care Community, 2007. 15(4): p. 313-21.

38. Mobach, M.P., Counter design influences the privacy of patients in health care. Soc Sci Med, 2009. 68(6): p. 1000-5.

39. Bednarczyk, R.A., J.A. Nadeau, C.F. Davis, A. McCarthy, S. Hussain, R. Martiniano, et al., Privacy in the pharmacy environment: Analysis of observations from inside the pharmacy. Journal of the American Pharmacists Association, 2010. 50(3): p. 362-367.

40. Knox, K., F. Kelly, A. Mey, L. Hattingh, J.L. Fowler, and A.J. Wheeler, Australian mental health consumers' and carers' experiences of community pharmacy service. Health Expectations, 2015. 18(6): p. 21072120.

41. Worley-Louis, M.M., J.C. Schommer, and J.R. Finnegan, Construct identification and measure development for investigating pharmacist-patient relationships. Patient education and counseling, 2003. 51(3): p. 229-38.

42. Butler, K.T., J.F. Ruisinger, J. Bates, E.S. Prohaska, and B.L. Melton, Participant satisfaction with a community-based medication synchronization program. Journal of the American Pharmacists Association : JAPhA, 2015. 55(5): p. 534-9. 
Table 1. Patient Characteristics ( $\mathrm{N}=\mathbf{2 5}$ )

\begin{tabular}{lcr}
\hline & Category & Frequency \\
\hline Gender & & \\
& Female & $18(72)$ \\
& Male & $7(28)$ \\
Age (years) & & \\
& & \\
& 50 & $3(12)$ \\
& $50-59$ & $6(24)$ \\
& $60-69$ & $12(48)$ \\
& $\geq 70$ & $4(16)$
\end{tabular}

Number of medications for chronic conditions

$\leq 4$

$11(44)$

5-6

$8(32)$

$>6$

$6(24)$

\section{Enhanced pharmacy services received}

Medication synchronization

$16(64)$

Immunization

$15(60)$

Disease state management

$11(44)$

Medication management

$10(40)$

Monitor the effect of medications

$9(36)$ 
Table 2. Pharmacy and Respondent Characteristics

\begin{tabular}{|c|c|}
\hline Category & Frequency (\%) \\
\hline $\begin{aligned} & \text { Type of pharmacy } \\
&$\[ \begin{aligned} \text { Independent } \\
\text { Large Chain } \\
\text { Supermarket }\end{aligned} \]$ \\
&\end{aligned}$ & $\begin{array}{l}3(50.0) \\
2(33.3) \\
1(16.7)\end{array}$ \\
\hline $\begin{array}{l}\text { Average number prescriptions/week } \\
\qquad \begin{array}{l}500-999 \\
1,000-2,000 \\
2,000 \text { or more }\end{array}\end{array}$ & $\begin{array}{l}1(16.7) \\
4(66.7) \\
1(16.7)\end{array}$ \\
\hline $\begin{array}{l}\text { Hours open/week (Mean=59.8) } \\
\qquad \begin{array}{c}48 \\
49 \\
68 \\
72 \\
74\end{array}\end{array}$ & $\begin{array}{l}2(33.3) \\
1(16.7) \\
1(16.7) \\
1(16.7) \\
1(16.7)\end{array}$ \\
\hline $\begin{array}{l}\text { Percent of providers within locale having a working relationship } \\
\qquad \begin{array}{l}1-20 \% \\
21-40 \% \\
41-60 \% \\
61-80 \% \\
81-100 \%\end{array} \\
\end{array}$ & $\begin{array}{l}1(16.7) \\
0 \\
1(16.7) \\
3(50.0) \\
1(16.7) \\
\end{array}$ \\
\hline $\begin{array}{l}\text { Number of other pharmacies within } 3 \text { miles } \\
\qquad \begin{array}{c}\text { None } \\
1-5 \\
6-10\end{array} \\
\end{array}$ & $\begin{array}{l}2(33.3) \\
3(50.0) \\
1(16.7)\end{array}$ \\
\hline $\begin{array}{c}\text { Respondent's degrees in pharmacy } \\
\text { PharmD } \\
\text { BSPharm } \\
\text { Masters } \\
\end{array}$ & $\begin{array}{l}4(66.7) \\
3(50.0) \\
1(16.7)\end{array}$ \\
\hline $\begin{array}{l}\text { Respondent's title } \\
\qquad \begin{array}{l}\text { Owner } \\
\text { Manager/Pharmacist in charge } \\
\text { Staff pharmacist }\end{array}\end{array}$ & $\begin{array}{l}3(50.0) \\
2(33.3) \\
1(16.7)\end{array}$ \\
\hline
\end{tabular}


Table 3. Practice Characteristics ( $n=6)$

\begin{tabular}{|l|c|c|c|c|}
\hline \multicolumn{1}{|c|}{ Category } & $\begin{array}{c}\text { Frequency } \\
\text { (\%) }\end{array}$ & $\begin{array}{c}\text { Minimum/ } \\
\text { Maximum }\end{array}$ & Mean & $\begin{array}{c}\text { Std } \\
\text { Dev }\end{array}$ \\
\hline $\begin{array}{l}\text { Number of FTE's } \\
\begin{array}{l}\text { Pharmacists \& residents } \\
\text { Pharmacy technicians }\end{array}\end{array}$ & - & $\begin{array}{c}1.0 / 5.5 \\
2.0 / 11.0\end{array}$ & $\begin{array}{c}3.5 \\
5.7\end{array}$ & $\begin{array}{l}1.7 \\
3.0\end{array}$ \\
\hline Hours/week RPh's provide patient care services & - & $12 / 52$ & 31.2 & 17.6 \\
\hline $\begin{array}{l}\text { Pharmacist's rating of their confidence of success in a } \\
\text { value-based network }\end{array}$ & - & $5 / 10$ & 7.0 & 1.79 \\
\hline Can view their elderly high risk medications & $6(100)$ & - & - & - \\
\hline $\begin{array}{l}\text { Manage diabetes, provide immunizations \& adherence } \\
\text { packaging, }\end{array}$ & $6(100)$ & - & - & - \\
\hline $\begin{array}{l}\text { Provide services for hyperlipidemia, medication } \\
\text { reconciliation, MTM, medication synchronization, } \\
\text { adherence management }\end{array}$ & $5(83.3)$ & - & - & - \\
\hline Provide chronic care management for Medicare & $5(83.3)$ & - & - & - \\
\hline Use an internal patient registry & $2(33.3)$ & - & - & - \\
\hline
\end{tabular}


Table 4. Themes from Service Quality Components and Maintaining Health

\begin{tabular}{|c|c|}
\hline Service Quality Components & Themes \\
\hline \multirow[t]{2}{*}{ Reliability } & 1.1 Patients appreciated the benefits of medication synchronization. \\
\hline & $\begin{array}{l}\text { 1.2 Patients found pharmacists instrumental in providing } \\
\text { immunizations. }\end{array}$ \\
\hline \multirow[t]{2}{*}{ Responsiveness } & 2.1 Patients valued pharmacists' readiness to serve. \\
\hline & 2.2 Pharmacists were responsive to patients' needs. \\
\hline \multirow[t]{3}{*}{ Access } & 3.1 Convenience was important for patients in selecting pharmacies. \\
\hline & 3.2 Patients living in small towns had limited choices. \\
\hline & 3.3 Patients were open to appointments when needed. \\
\hline Security & 4.1 Patients didn't see problems with privacy in pharmacies. \\
\hline Competence & 5.1 Patients recognized pharmacists' knowledge about medications. \\
\hline \multirow[t]{2}{*}{ Credibility } & 6.1 Patients trusted advice from pharmacists on medications. \\
\hline & $\begin{array}{l}\text { 6.2 Patients believed the importance of good relationship with } \\
\text { pharmacists. }\end{array}$ \\
\hline Communication & 7.1 Patients rated communication with pharmacists highly. \\
\hline $\begin{array}{l}\text { How pharmacists help patients } \\
\text { maintain health }\end{array}$ & $\begin{array}{l}\text { 8.1 Patients viewed medication provision as pharmacists' role in } \\
\text { maintaining their health. } \\
\text { 8.2 Not all contributions of pharmacists to patient health are } \\
\text { apparent. }\end{array}$ \\
\hline
\end{tabular}

